\title{
DAMPAK RFID PADA STOK BARANG RETAILER
}

\author{
I Gusti Made Karmawan
}

\author{
Computerized Accounting Department, School of Information Systems, Binus University \\ Jln. K.H. Syahdan No. 9, Palmerah, Jakarta Barat 11480 \\ karmawan65@yahoo.co.id
}

\begin{abstract}
The development of RFID technology (Radio Frequency Identification) offers some advantages, especially in goods distribution, supply chain and logistics. This technology works by putting a chip on an item as a replacement for barcodes that are widely used today. With the RFID technology, the process of goods identification becomes very easy and fast. Therefore, some large companies have started implementing and trust the system, especially the supermarket retailers although there are still some problems encountered in the application of this system, related to issues of privacy and data integrity problems. This paper discusses how RFID works and the impacts to the company related to profits and problems encountered during the application of this system.
\end{abstract}

Keywords: RFID, goods distribution, goods identification

\begin{abstract}
ABSTRAK
Teknologi RFID (radio frequency identification) yang berkembang saat ini memberikan penawaran dalam beberapa keunggulan, terutama dalam pendistribusian barang-barang, supply chain dan logistik. Teknologi ini berupa peletakan chip di suatu barang sebagai pengganti barcode yang sudah banyak dipakai saat ini. Dengan adanya teknologi RFID, proses identifikasi barang menjadi sangat mudah dan cepat. Oleh karena itu beberapa perusahaan besar sudah mulai mengimplementasikan dan mempercayai sistem ini, khususnya retailer untuk supermarket walaupun masih ada beberapa masalah yang dihadapi dalam penerapan sistem ini, terkait masalah privasi dan masalah integritas data. Paper ini akan membahas cara kerja RFID dan bagaimana dampak RFID dalam suatu perusahaan terkait keuntungan dan masalah yang dihadapi dalam penerapan sistem ini.
\end{abstract}

Kata kunci: RFID, pendistribusian barang, identifikasi barang 


\section{PENDAHULUAN}

Majunya teknologi pada masa kini semakin pesat. Banyak teknologi-teknologi canggih baru dibuat. Salah satu contohnya adalah RFID (Radio Frequency Identification). RFID adalah teknologi yang menggunakan frekuensi radio dalam mengirim informasi antara RFID tag dan RFID reader. Teknologi RFID ini sama dengan IFF transponder yang sudah ditemukan pada Perang Dunia II di Inggris. Penerapan teknologi RFID sekarang ini sudah mulai menyebar ke semua bidang, terutama pada bidang-bidang yang sensitive keamanan. Bahkan saat ini chip sudah dimasukkan ke bagian tubuh manusia sebagai tanda pengenal pribadi.

Teknologi RFID ini dapat menjawab beberapa kelemahan teknologi sebelumnya. Sebagai contoh, barcode. Barcode saat ini mulai digantikan oleh RFID karena RFID tidak perlu kontak langsung antar reader dan tag-nya. RFID menggunakan pengiriman gelombang elektromagnetik. Selain itu, RFID juga dapat menyimpan informasi dan informasi yang tersimpan tersebut dapat diganti, berbeda dengan barcode, yang sulit untuk mengganti informasi yang sudah ada di dalamnya.

Menurut Stephen A. Weis "One familiar optical barcode is the Universal Product Code (UPC) designed in 1973” (Stephen A. Weis, 2003:30) dan banyak di gunakan pada banyak produk untuk konsumen. Teknologi barcode memang sudah ada dalam pengolahan barang saat ini, tetapi ada kekurangan yang berhubungan dengan sifat fisik barcode tersebut, yaitu: sulit dibaca di barang lentur, mudah hilang kehitamannya, hanya memberi sedikit informasi, tidak fleksibel dalam pembacaannya. Garfinkel (2002) telah mengkonversi barcode scan optik ke tag RFID baru dan klaim bahwa latters memiliki advantags serveral.

Teknologi RFID banyak dimanfaatkan untuk membantu permasalahan dalam mengidentifikasi objek/barang, juga dalam mengidentifikasi lokasi suatu barang. RFID dapat digunakan dalam supermarket untuk update stok dan mengidentifikasikan stok tersebut. Teknologi RFID dapat mempermudah dan mempercepat pengidentifikasian stok dalam sebuah supermarket. Kemudahan yang didapat antara lain: (1) smart shelf yang berbasis RFID dapat mengidentifikasi keberadaan setiap item pada sebuah rak. Ketika item diambil, sistem akan mendeteksi item yang diambil oleh pelanggan, memberi tanda dan mencatat item yang diambil, sehingga dapat dilakukan real-time shelf inventory; (2) laporan tentang inventory dapat diketahui secara real-time, maka retailer bisa mendapatkan laporan yang up-to-date mengenai stok barang; (3) retailer dapat mengurangi masalah kekurangan stok yang dapat mengakibatkan 'lost sales'; (4) meningkatkan keamanan barang dengan adanya RFID tag.

Dalam penelitian ini, ruang lingkup yang dibahas adalah: (1) sistem pendistribusian dan pergudangan pada retailer dengan menggunakan teknologi RFID untuk mengidentifikasi barang yang masuk dan keluar, kondisi barang dan posisi barang tersebut. Sistem ini dirancang untuk mempermudah masuk dan keluarnya barang dari gudang dan penjualan barang di retailer; (2) perbandingan cara kerja fungsi-fungsi dan kelebihan yang dimiliki RFID; (3) perbandingan keunggulan antara RFID dan barcode; (4) bagaimana RFID membantu suatu retailer dan dampak positif dan negatif yang dibawa oleh RFID.

Adapun tujuan yang ingin dicapai dalam penelitian ini yaitu: (1) menjelaskan mengenai teknologi yang dapat melengkapi kekurangan barcode; (2) memberikan pengetahuan mengenai teknologi RFID; (3) menjelaskan sistem pendistribusian barang dengan bantuan RFID. Dan manfaat yang dapat diperoleh adalah mengetahui manfaat RFID dan penggunaannya. 


\section{METODE}

Metode yang digunakan penulis adalah metode studi pustaka dengan mengumpulkan data melalui buku, internet dan sumber lain yang mempunyai dasar yang penting untuk memproses data penelitian ini. Penelitian yang dilakukan berkaitan dengan RFID (perangkat, cara kerja), serta hal-hal yang berkaitan dengan stok barang, barang masuk dan barang keluar.

\section{HASIL DAN PEMBAHASAN}

\section{Perangkat RFID}

RFID terdiri dari beberapa perangkat, yaitu: RFID tag, RFID reader, antenna, dan controller.

\section{RFID Tag}

Tag RFID adalah perangkat yang dibuat dari rangkaian elektronika dan antena yang terintegrasi di dalam rangkaian tersebut. Rangkaian elektronik dari tag RFID umumnya memiliki memori sehingga tag ini mempunyai kemampuan untuk menyimpan data. Memori pada tag secara dibagi menjadi sel-sel. Beberapa sel menyimpan data read only, misalnya serial number yang unik yang disimpan pada saat tag tersebut diproduksi. Sel lain pada RFID mungkin juga dapat ditulis dan dibaca secara berulang.

RFID tag terdiri dari dua bagian, yaitu: (1) inlay - adalah inti/utama dari RFID tag yang terdiri dari chip dimana informasi disimpan. Inlay ini berbentuk kecil dan mudah rusak, sehingga RFID tag yang digunakan selalu dalam bentuk encapsulated. Informasi yang disimpan berupa: informasi permanen yang dibuat saat pembuatan yang berisi ID unik dari tag. Informasi ini tidak dapat diubah. Dan informasi non-permanen yang dapat ditulis oleh aplikasi dengan bantuan RFID reader; (2) encapsulation/Bungkus inlay - karena bentuk inlay yang rapuh, perlu dilakukan encapsulation. Pemakaian encapsulation memberi keuntungan bagi solusi RFID karena material encapsulation dapat disesuaikan dengan kondisi yang cukup kacau, seperti temperature dan kelembaban, lingkungan yang kotor, maupun kondisi operasional yang banyak benturan.

Menurut klasifikasi, tag dibedakan menjadi tiga, yaitu: aktif, semi-pasif dan pasif. Tag aktif mempunyai sumber tenaga seperti baterai dan dapat dilakukan komunikasi untuk dibaca dan ditulis. Tag semi-pasif mempunyai baterai tetapi hanya dapat merespon transmisi yang datang (incoming transmissions). Tag pasif menerima tenaga dari reader, antena yang akan menjadi sumber tenaga dengan memanfaatkan medan magnet yang ditimbulkan dari pembaca (reader).

Ada 4 macam RFID tag yang sering digunakan, dikategorikan berdasarkan frekuensi radionya: (1) low frequency tag (antara $125 \mathrm{ke} 134 \mathrm{kHz}$ ) - banyak digunakan untuk identifikasi pada binatang, beer keg tracking, keylock pada mobil dan juga sistem anti pencuri. Binatang peliharaan seringkali ditempeli dengan chip, ini membantu agar mereka dapat dikembalikan ke pemiliknya jika hilang; (2) high frequency tag $(13.56 \mathrm{MHz})$ - sering digunakan pada perpustakaan atau toko buku, pallet tracking, akses control pada gedung, pelacakan bagasi pada pesawat terbang. Ini digunakan untuk menggantikan kartu magnetik sebelumnya; (3) UHF tag (868 sampai $956 \mathrm{MHz}$ ) - sering digunakan secara komersil pada pallet dan pelacakan container, pelacakan truk dan trailer pada pelabuhan kapal; (4) microwave tag $(2.45 \mathrm{GHz})$ - seringkali digunakan untuk akses control jarak jauh kendaraan bermotor. 


\section{Tag RFID Aktif:}

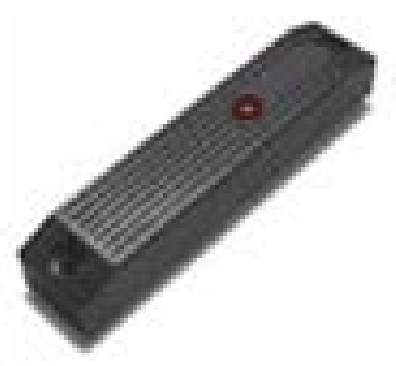

TAG RFID Pasif :

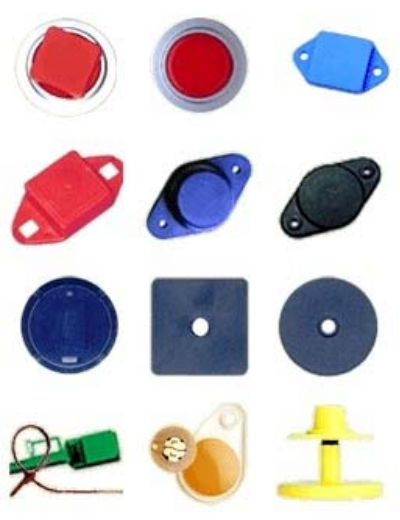

Gambar 1. Tag RFID aktif dan pasif.

\section{RFID Reader}

Berdasarkan mobilitas reader-nya RFID dibedakan menjadi: (1) mobile RFID reader/terminal RFID reader ada dua model: internal (sudah terintegrasi dengan mobile terminal) dan eksternal (dalam bentuk CF card dan bluetooth koneksi); (2) vehicle-mounted RFID reader - dipasang pada kendaraan/forklift yang dipakai untuk kegiatan peletakkan/put-away maupun pengambilan/picking dari pallet atau barang yang telah dilekatkan RFID tag; (3) fixed RFID reader - dipakai dalam penerapan "fixed reading gate". Dalam hal ini, item secara fisik akan dibawa kedalam area baca dari reader yang bersifat stastioner. Contoh: access control. Fixed reader memiliki dua model: dengan antenna yang sudah terintegrate dan antenna eksternal. Berikut contoh RFID reader (Gambar 2).

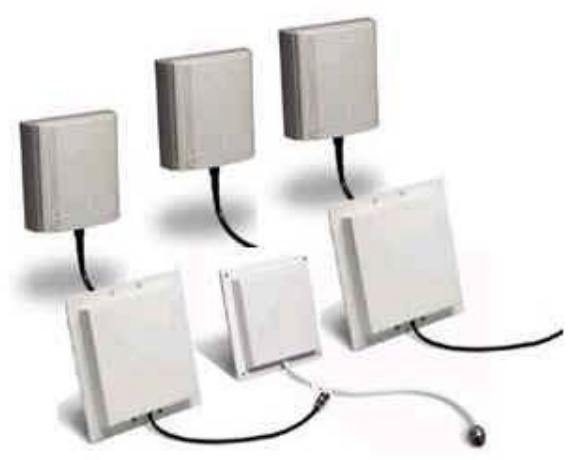

Gambar 2. RFID reader.

\section{Antenna}

Antenna adalah unsur yang penting untuk menentukan jarak baca antara reader dengan RFID tag dan juga seberapa luas area pembacaan. Ada beberapa hal yang harus diperhatikan oleh satuan antenna, yaitu: penguatan antenna, polarisasi gelombang, dan bentuk antenna.

Dari kebutuhan pengoperasian, antenna dapat dikategorikan dalam dua model koneksi: (1) integrated antenna - untuk jarak baca pada satu posisi saja dengan jarak $<50 \mathrm{~cm}$ dan luas area pembacaan sangat terbatas ( $<1 \mathrm{~m})$. Contoh: stock control, inventory; (2) external antenna - dibutuhkan jika cara pembacaan lebih dari satu posisi dan luas area pembacaan $>1 \mathrm{~m}$ (antenna akan terhubung ke "fixed reader" dengan port antenna maksimal 8 port). 


\section{Controller (sering disebut juga Host)}

Umumnya berbentuk sebuah PC atau workstation yang memiliki fungsi database dan juga kontrol (biasa disebut middleware).

\section{Cara Kerja RFID}

Tag dan reader berkomunikasi menggunakan gelombang radio. Saat suatu objek yang telah ditempeli tag memasuki zona baca dari suatu reader, gelombang radio yang dipancarkan oleh reader tersebut akan membangkitkan/ mengaktifkan suatu sirkuit pada tag yang lalu akan memancarkan/mentransmisikan informasi apa yang disimpan di tag tersebut. Tag dapat berisi berbagai macam informasi seperti nomor seri, timestamp, instruksi konfigurasi, dan lain-lain.

Setelah reader mendapatkan informasi yang dimiliki suatu tag, informasi tersebut akan dikirim ke controller melalui berbagai koneksi yang mungkin (bisa melalui kabel, wireless LAN, internet, atau bluetooth). Controller kemudian akan menggunakan informasi yang didapat untuk berbagai tujuan yang telah ditetapkan sebelumnya. Misalnya controller dapat saja hanya menyimpan data tersebut di database inventorisnya atau bisa juga mengatur agar barang yang ditempeli tag tersebut dikirim ke tempat tertentu.

Suatu sistem RFID dapat terdiri dari banyak reader yang dapat dihubungkan ke suatu controller yang berdiri sendiri ataupun bekerja sama dengan controller lainnya.

Cara kerja ini terangkum dalam Gambar 3.
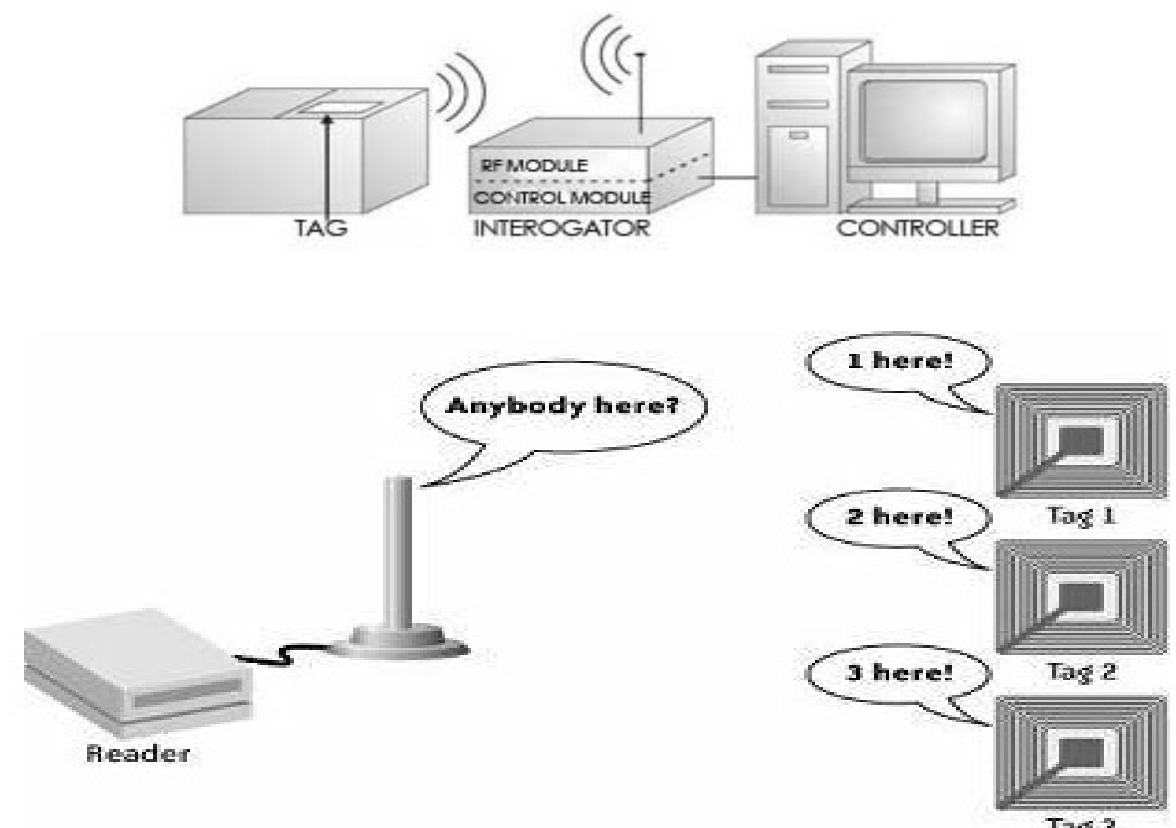

Gambar 3. Cara kerja RFID.

\section{Isu dalam Penggunaan RFID}

Penggunaan RFID juga mengundang berbagai kontroversi. Ada empat alasan sehubungan privasi dalam penggunaan RFID, yaitu: (1) pembeli suatu barang (yang dilengkapi RFID tag) tidak 
akan tahu keberadaan dari RFID tag atau bahkan tidak dapat untuk melepasnya; (2) RFID tag dapat dibaca oleh pihak lain dalam jarak yang jauh tanpa sepengetahuan pemiliknya; (3) jika suatu barang yang mengandung RFID tag Anda beli dengan menggunakan kartu kredit, akan sangat mungkin untuk mengasosiasikan ID tersebut dengan identitas si pembeli; (4) EPCglobal sedang membuat suatu standar untuk memberikan suatu ID yang unik secara global dan ini dikhawatirkan akan menimbulkan masalah privasi dan juga masih belum begitu perlu untuk beberapa aplikasi.

\section{Manfaat RFID bagi Pedagang}

Adapun manfaat penggunaan RFID bagi pedagang sebagai berikut:

\section{Real Time Inventory Information}

RFID dapat membantu pedagang untuk mewujudkan real-time inventory information yang dapat membantu mengurangi kehabisan stok, mengidetifikasikan lokasi barang. Manfaat dari real-time inventory information ini memungkinkan pedagang untuk memberikan pelayanan yang lebih baik kepada pembeli dan menaikkan penjualan.

\section{Mengurangi Biaya Pegawai}

Diperkirakan bahwa RFID dapat membantu pedagang secara efektif untuk mengurangi biaya di beberapa area: penerimaan barang (50\%-65\%), bagian stok (22\%-30\%), pengeluaran barang (22\%-30\%), perputaran barang (40\%-60\%), dan perhitungan fisik (90\%-100\%).

\section{Mengurangi Pencurian}

RFID dapat membantu mengurangi pencurian, karena dengan sensornya dapat memberi peringatan kepada staff jika barang dipindahkan secara ilegal atau jika barang telah dipindahkan ke tempat yang salah. Persediaan juga dapat diberi peringatan jika barang tidak lagi layak untuk dikonsumsi, tidak diminati konsumen atau barang rusak.

\section{Peluang yang Berintegritas}

Selain untuk meningkatkan Supply Chain, munculnya teknologi RFID menawarkan pedagang peluang penjualan yang lebih baik. RFID dapat melacak barang yang dibeli pelanggan dan dapat member penawaran barang lain selama pembeli sedang berbelanja. Ini dapat mendorong pembeli untuk membeli lagi.

\section{Masalah RFID bagi Pedagang}

RFID juga bisa menimbulkan beberapa kerugian bagi pedagang, yaitu: (1) biaya dan perhitungan investasi - biaya RFID ini dianggap sebagai tambahan biaya dalam perhitungan ROI, karena sulit untuk memperkirakan perhitungan biaya yang disimpan karena adanya RFID ini; (2) masalah perangkat - suksesnya integrasi sistem informasi persediaan adalah hal penting untuk mempertimbangkan reknologi RFID. Perangkat yang mendukung adalah dengan RFID reader menyaring dan mengagregatkan informasi dan mengarahkan data ke sistem perusahaan seperti sistem manajemen gudang. Masalah yang dihadapi adalah kualitas data dan control; (3) tanggapan konsumen - kepuasan pelanggan naik setelah menggunakan sistem ini. Namun, tidak semua pelanggan menyukai dan menggunakan kemajuan teknologi ini. Ada beberapa pelanggan yang lebih memilih ke toko biasa dibanding toko ini. 


\section{RFID vs Barcode}

Walaupun murah dan sudah banyak dipakai, ternyata barcode mempunyai kekurangan di beberapa bidang. Selain harus mendekatkan barcode ke mesin reader untuk membaca, barcode juga mempunyai kekurangan lain, yaitu kapasitas penyimpanan memorinya yang terbatas dan tidak memungkinkan untuk memprogram ulang, sehingga tidak memungkinkan untuk memperbarui data barang. Maka, solusi lain untuk mengatasi kekurangan barcode ini adalah dengan munculnya RFID. RFID adalah Radio Frequency Identification. RFID merupakan teknologi untuk mengidentifikasikan objek secara otomatis dengan menggunakan gelombang radio.

Keuntungan RFID dibandingkan dengan Barcode antara lain: (1) proses pengidentifikasian RFID lebih cepat; (2) RFID tahan terhadap kondisi kotor dalam pembacaannya; (3) RFID dalam pengoperasiannya tidak memerlukan kontak secara langsung; (4) RFID lebih susah digandakan atau di copy.

Perbandingan kemampuan RFID dengan barcode adalah sebagai berikut (Tabel 1)

Tabel 1

Perbandingan Kemampuan RFID dengan Barcode

\begin{tabular}{lll}
\multicolumn{1}{c}{ Perbandingan } & \multicolumn{1}{c}{ Barcode } & \multicolumn{1}{c}{ RFID } \\
\hline Posisi baca & Vertikal / horizontal dengan toleransi tertentu & Bebas, memenuhi segala kondisi \\
\hline Kecepatan baca & Relatif (2-5 detik) & $<100$ milidetik per item \\
\hline Jarak baca max & $\pm 7 \mathrm{~cm}$ & $\pm 30 \mathrm{~cm}$ \\
& & $\pm 3 \mathrm{~m}$ \\
& & $\pm 10 \mathrm{~m}$ \\
\hline Kemampuan & Read only & Read and write \\
\hline Kapasitas memori & Kecil & 64 kb atau lebih \\
\hline Proses Pembacaan & Per item (proses 1 per 1) & Multi item per proses \\
\hline Kondisi buruk & Apabila label barcode rusak, pembacaan menjadi idak berpengaruh \\
& error & Tidak \\
\hline Kemudahan & Mudah & Hampir mustahil \\
duplikasi & & \\
\hline Ukuran data & 1-100 byte & 128-8096 byte \\
\hline Transmisi data & Optik & Electromagnetik \\
\hline
\end{tabular}

\section{Penggunaan RFID oleh Perusahaan Wal Mart}

Penggantian sistem dari barcode menuju RFID ini dilakukan oleh perusahaan Wal Mart. Wal Mart mengganti sistem pengolahan, sistem informasi dan database perusahaan. Barang yang didistibusikan kini ditempel RFID sebagai tanda pengenal. Chip RFID ini akan dikenali oleh sensor di pintu gudang. Chip RFID ini menyimpan semua data tentang barang tersebut, dari produsen, warna, bentuk, kualitas barang dan sebagainya. Dengan begini, Wal Mart menghemat beberapa jam dalam distribusi barang.

Langkah selanjutnya, Wal Mart juga banyak melakukan perbaikan dalam bidang sistem informasi, dengan pemasangan radio satelit pada setiap truk pengangkut barang. Implikasinya, truk pengangkut barang ini dapat seketika berubah arah ke cabang yang lebih membutuhkan barang. Ini dapat meningkatkan efisiensi pengiriman/distribusi barang. Efisiensi ini dapat menambah pemasukan lagi. Penggunaan RFID menggantikan barcode terbukti meningkatkan efisiensi waktu yang sangat banyak. Petugas gudang tidak perlu menghabiskan waktu yang cukup lama untuk memeriksa barang 
yang keluar dan masuk. Pekerjaan yang biasa dilakukan dalam beberapa jam kini dapat dilakukan dengan beberapa detik.

Selain untuk distribusi barang, RFID ini juga membantu Wal Mart menganalisis database barang. Barang apa saja yang laku di saat-saat tertentu. Wal Mart dapat menjaga stok barangnya agar barangnya tetap dapat mengalir. Dan juga kepuasan pelanggan dapat terpenuhi. Penyusunan barang di rak juga merupakan hasil analisa tren kebutuhan pelanggan. Setelah barang diletakan ke rak, penjualannya dimonitor dari hari ke hari. Barang yang lama terjual akan didistribusikan ke cabang lain. Grafik penurunan harga RFID (Gambar 4) mempengaruhi jumlah pemakaian RFID. Semakin rendah harga RFID, semakin banyak pula pemakainnya dari tahun ke tahun.

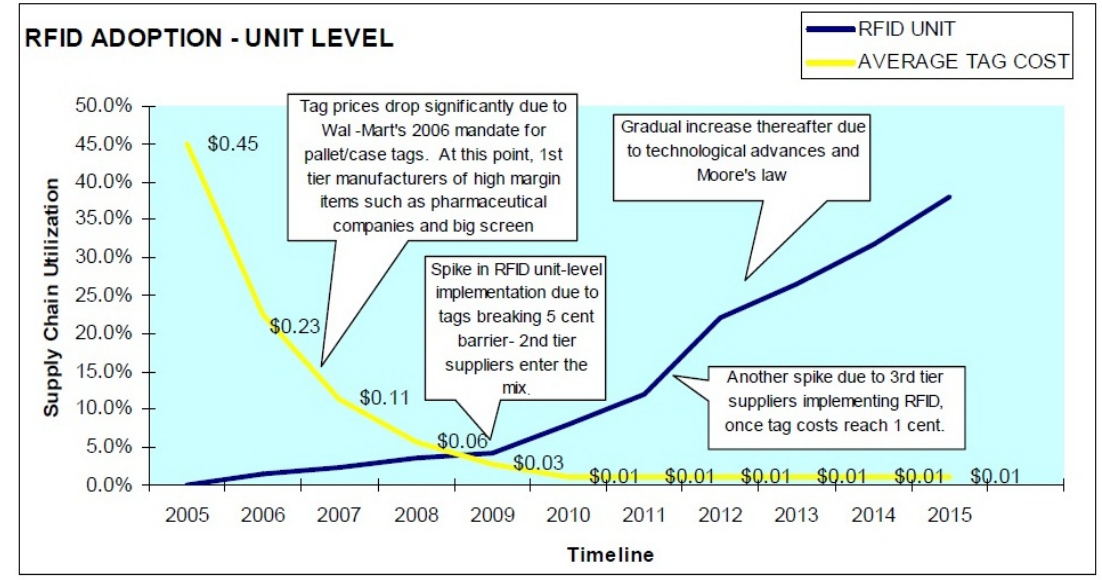

Gambar 4. Grafik penurunan harga RFID.

Pada tahun 2006, Wal Mart membantu mengurangi biaya RFID tag. Ini dapat mendorong pedagang lainnya untuk ikut menggunakan RFID tag melihat skala ekonomi dan penghematan biaya pemasokkan yang dikurangi oleh tekologi RFID ini. Wal Mart mengimplementasi teknologi RFID untuk memperkuat rantai distribusinya dan mempermudah pencatatan inventory yang masuk dan keluar selama perputaran.

Setelah dicatat, dampak Wal Mart setelah menggunakan RFID dalam keuntungannya adalah: (1) Wal Mart dapat mengeliminasi para petugasnya (petugas yang bekerja untuk meng-scan code bar, menghitung barang gudang) sebanyak 15\%, kira- kira sebesat \$6,7 Billion; (2) masalah yang biasa dihadapi penjual adalah masalah out-of-stok, masalah ini dapat diatasi oleh Wal Mart dan dapat memberikan profit sebesar \$600 Million; (3) dapat mengetahui dimana produknya tiap saat, ini membuat barang Wal Mart sulit untuk dicuri, dapat diatasi nya maslah ini, dapat memberikan Wal Mart keuntungan sebanyak \$575 juta; (4) biaya untuk pelacakan atau pencarian barang yang sedang didistribusikan biasanya mengeluarkan biaya, namun sekarang biaya itu dapat dihemat sebesar $\$ 300$ juta; (5) peningkatan pengetahuan akan produk apa yang ada dalam rantai perputaran dan produk apa yang tidak ada dalam rantai perputaran membuat Wal Mart dapat mengatur stok inventorynya. Ini memberi keuntungan untuk Wal Mart sebanyak \$180 juta.

\section{PENUTUP}

RFID merupakan solusi untuk kekurangan barcode dan dapat memenuhi kebutuhan seharihari sebagai perangkat yang dapat member kemudahan bagi hidup manusia. Dengan menggunakan 
teknologi RFID ini, memungkinkan suatu pusat retail untuk menerapkan system update stok secara real time. System dengan menggunakan RFID ini membuat system lebih efisien dan menghemat waktu dibandingkan dengan system manual maupun system menggunakan barcode.

Penghematan yang dapat dilakukan dengan menggunakan system RFID ini adalah waktu, tenaga dan biaya. Dengan system RFID ini juga dapat membantu manager untuk memahami keinginan pelanggan sehingga manager dapat mengatur stok barang dan menyediakan barang sesuai dengan kebutuhan pelanggan.

Namun, harga RFID masih tergolong mahal untuk melengkapi persediaan dalam jumlah banyak. Selain itu, privacy pun menjadi masalah dalam penggunaan ini. Dua hal yang menjadi isu privacy yang ditakuti oleh masyarakat adalah pelacakan tersembunyi dan pengumpulan data secara diam-diam. Karena tag RFID tidak memiliki control akses sehingga sembarang reader dapat menginterogasinya.

\section{DAFTAR PUSTAKA}

Granfinkel, S. L (2002). Adopting fair information practices to low cost RFID system. Paper presented at Ubiquitous Computing 2002, Privacy workshop. Diakses dari httpx//www.Sisson.net/chips/academic/2002 Ubicomp_RFID.pdf.

Masters Thesis tidak diterbitkan. Massachusetts Institute of Technology, Massachussetts.

Weis, Stephen A. (2003). Security and Privacy in Radio-Frequency Identification Devices. 